\title{
CORRESPONDENCE
}

\section{Biologists mis-cite}

SIR,-The importance of checking original sources is well recognized, but doing so becomes harder as the literature grows. I describe here an attempt at quantification of the reliability of citations.

Since familiarity with the cited literature is essential, I selected 28 of my own, not faultless, publications and 136 related publications by other authors. These deal mostly with snail physiology and with ionic and acid-base regulation in animals.

Errors found include misquotation of quantitative data, confusion of hypothesis with fact, of crustaceans with molluscs, of one species with another and of experimental variations with natural variations; also invention, simplification and statements contrary to what was demonstrated. Along with 33 such errors occurring in 29 citing publications are 11 instances of correct information being used with a wrong reference, or with none. Some of the correct citations were almost too simple to be capable of being wrong (such as "Recent investigations include that of. . "). Such citations can be useful, but at least 12 citing publications include apparently pointless references to the cited publications or, more important, omit others known to the authors that are clearly of greater relevance.

There are 3 instances of references being given in the text, but not in the bibliography, and 4 mistakes of the opposite kind. Of the 205 entries in the 136 bibliographies, 14 contain mistakes that could hinder, though not prevent, the location of articles (wrong page number, year or publisher). Other, mostly trivial slips, including altered punctuation and omission of words or letters, occur in a further 55 references, sometimes several in each. 58 of the bibliographies contain at least one error. Most errors are in titles, which, in accordance with editorial policies, many of the other references do not include.

Fifty-six per cent of the citing publications contained at least one of the above faults. Especially in bibliographies, slips must often be due to hasty note-taking before citation is specifically envisaged; the original lack of care may then be forgotten during preparation of the manuscript. Blanchard 1 , in a letter since misrepresented in print, has described (I think) how he found that, of 6 references to a particular paper in chemistry, 4 contained errors in volume or page number. The assessment concerning the appropriateness of some of the citations is subjective, but is a reminder that other factors may influence an author's choice of citations than the interests of the reader 2,3 .

\section{Institute of Physiology \\ University of Glasgow}

Glasgow G12 $8 Q Q$, UK

\section{References}

. Blanchard, D.C. Science 185, 1003 (1974)

May, K.O. Science 156, 890-892 (1967)

Garfield, E. Current Contents, Life Sci. 23, 5-9 (1980)

\section{Chemical warfare}

Sir, - Your leading article of 10 July makes the point that verification of an agreement to ban chemical weapons, which was never easy, becomes even more difficult in relation to production of the components of binary chemical munitions. An alternative approach, assuming that an agreement had been reached, might be to monitor the stockpiling and/or issue of protective clothing (especially gas masks) for military or civilian use, and any military exercises in such clothing. If the major powers had entered into the agreement in good faith there would be no need for clothing capable of protecting against nerve agents, and certainly not of military exercises by troops wearing it. It is very unlikely that a country intending to use chemical weapons could do so without making preparations to protect its own personnel on a scale which would escape detection by the intelligence organizations of the other countries which were party to the agreement. From an agreed date, after sufficient countries had ratified the agreement, all clothing for protection against nerve gases would go into bonded stores, and any military exercises involving such clothing would be forbidden.

If the argument is valid, such an indirect monitoring should suffice to detect any intention to infringe the agreement - even though the most important factor remains confidence that in no country do chemical weapons serve its people's real interests.

17 Mortimer Crescent J.H. HUMPHREY London NW6 5NP, UK

\section{Budapest disclaimer}

SIR,-Your article by Vera Rich ( 5 June) refers to an interview with me at the Budapest International Fair. Having studied the contents of the article, I must state with the utmost regret that it lacks the desired accuracy. I therefore feel it appropriate to correct the article at some points.

At the beginning of our talk I conveyed to Miss Rich that as the Hungarian Academy of Sciences was not a participant at the 1980 Budapest International Fair, academic research was not being presented at this event. I explained that at the exhibition, in accordance with Hungarian science policy, attention was drawn to scientific results serving practical benefits and achieved at universities and other institutes of higher education within the sphere of the Ministry of Education. Furthermore, I emphasized that great effort has been and is still exercised by the Ministry of Education towards putting research results into practice as soon as possible, thus promoting progress in our country. Universities agree with us in setting these goals, as was confirmed by the fair. I continued by emphasizing the importance of the demand made by users in connection with practical research, but I did not say "We make what foreigners want to buy"

In the course of the ensuing discussion, Miss Rich raised the question of how our scientists react to research being directed towards practical purposes. In answer, I said that the great majority seems to exercise the necessary goodwill in this respect but that not everybody is fit to fulfill the demands required by practical research.

In this sense, the statement attributed to me in the article that I do not agree with the pragmatic orientation of our research policy is incorrect; what I said was that the intention of the authorities of giving a pragmatic orientation to research policy causes some of our scientists anxiety. Accordingly I cannot accept, being myself also an advocate of emphasizing the need for practical research the statement attributed to me that "It is a pragmatic solution to direct more scientists to industry and not good for research".

I do not know which facts led Miss Rich to the conclusion that we place less emphasis on the socialist virtue of the development of scientific research in Hungary. I am convinced that this could only be a misunderstanding.

GYÖRGY PÁRIS

23 Szerb Street

H-1056 Budapest

Hungary

VERA Rich writes: I should feel most distressed if misunderstandings cloud $\mathrm{Mr}$ Paris's recollections of what I remember as a most friendly and open conversation.

Although the Academy of Sciences was not, however, exhibiting this year, the pavilion was clearly marked on the official plan as housing, inter alia, the Academy. If, because of interpretation difficulties, I have inadvertently confused views that $\mathrm{Mr}$ Paris put forward on his own behalf with views he quoted from scientists who disagree with him, I would wish to point out, in tendering him my apologies, that it is by no means common to meet an official spokesman who is ready both to put his own view and to quote his opponents.

\section{Adjectival concerns}

SIR, - I suggest that we generalize the convention implicit in the naming of the Earth's year. We suffer from a surfeit of planetary adjectives - should one speak of the mercuric or mercurial year, the saturnian, saturnine or saturnalian? Can one, in a reputable journal, mention the venereal or uranal year? How much simpler to name the planetary years ymer, yven, year, ymar, yjup, ysat, yura, ynep and yplu! How fortunate that $y$ is both vowel and consonant?

Peter Rastal 1

Department of Physics

University of British Columbia

Vancouver, British Columbia

Canada V6T I W5

\section{Unsplit infinitives}

Dr Glascock from Reading's an erudite man, Full of wit and grammatical zeal; In Naturel this May, he asked for a ban On the customary scientists' spiel.

Speak active, not passive, Dr Glascock advised;

Attach participles where they belong.

Above all be sure that you are apprised

Of how syntax matters in song.

Alas (and alack), as they say in some places,

The verses we liked but we shortened the missive.

One way and another, the result was red faces; Nature had split one of Glascock's infinitives!

Much worse was to coine, to readers' chagrin. Good Garton noticed the error ${ }^{2}$

And promptly blamed Glascock, not Nature, for $\sin$.

What anger, what shock and what horror!

Nature now tenders both Garston and Glascock

Regrets for its error and shame;

What verbs should be split is for authors to say

It is we who shoulder the blame.

The moral's quite clear, as we know too well The jargon leaves much to desire.

But do not rely upon rhymed doggerel

And to Belloc do not aspire.

Editor,Nature

1. Nature 8 May p.66.

2. Nature 12 June p.434. 